\title{
Estimation of correlations between ewe litter size and maternal effects on lamb weights in Merino sheep
}

\author{
Mohamed Analla $^{\text {a*}}$, Juan Manuel Serradilla ${ }^{\mathrm{b}}$ \\ a Department of Biology, The Abdelmalek Essaadi University, \\ P.O. Box 2121, 93002 Tetouan, Morocco \\ ${ }^{\mathrm{b}}$ Department of Animal Science, University of Cordoba (ETSIAM), \\ P.O. Box 3048, 14080 Cordoba, Spain
}

(Received 16 September 1997; accepted 2 July 1998)

\begin{abstract}
Data corresponding to weights from birth to 90 days of age of 4425 lambs, and to 3355 litters at lambing of 964 ewes, taken from 1987 to 1995 were used. The main objective of the study was to quantify the possible relationship between litter size of the ewes and their maternal effects on offspring weights. The results showed that the additive genetic correlation between litter size and the maternal component of weight is zero. The additive genetic correlation was low between litter size and the direct component of weight, and was similar to the correlation between permanent environmental effects for litter size and maternal permanent environmental effects for weights. In view of the results obtained, no complication should be expected if the local Merino breed could be oriented to the production of high quality females (improving their litter size and maternal abilities) to be used in terminal crosses for lamb meat production. (C) Inra/Elsevier, Paris
\end{abstract}

sheep / weight / litter size / maternal effects / correlations

Résumé - Estimation des corrélations entre la prolificité des brebis et les effets maternels sur les poids des agneaux dans la race Mérinos. Les données utilisées correspondent aux poids mensuels depuis la naissance jusqu'à 90 jours d'âge de 4425 agneaux, et 3355 mises-bas de 964 brebis, collectées de 1987 à 1995. Le principal objectif de ce travail a été de quantifier la relation possible entre la prolificité des brebis et leurs influences maternelles sur les poids de la descendance. Les résultats obtenus montrent que la corrélation génétique additive entre la prolificité et l'effet maternel est négligeable. Cette même corrélation entre la prolificité et la composante additive directe des poids est faible, et diminue avec l'âge des agneaux. Elle est similaire à la corrélation entre l'effet environnemental permanent sur la prolificité

\footnotetext{
* Correspondence and reprints

E-mail: analla@fst.ac.ma
} 
et l'effet environnemental permanent maternel sur les poids des agneaux. À partir de ces résultats, rien ne s'oppose à ce que la race locale Mérinos soit orientée vers la production de femelles de bonne qualité (prolificité élevée et bonne aptitude maternelle) pour être utilisée en croisement industriel pour la production de viande d'agneaux. (C) Inra/Elsevier, Paris

ovin / poids / prolificité / effets maternels / corrélations

\section{INTRODUCTION}

In lamb meat production systems ewes play a double role. They contribute directly to the number of lambs sold through their litter size, and indirectly, through the so-called maternal components, to the survival and growth of the lambs [4], and consequently, on final weight and number of lambs sold. Knowledge of the relationship between these two contributions will enable a better understanding and allow modelling of improvement strategies for meat sheep production. Correlations between litter size and weights in sheep were estimated first by Davis and Kinghorn [7] in a line of Merino sheep, and more recently by Analla et al. [2] in the Segureña breed. In both works the maternal components were not considered in the analysis. Moreover, no estimates of the relationships between litter size of ewes lambing and the corresponding maternal effects on their offspring weights are currently available. The aim of this work is to identify and quantify the possible relationships (genetic and environmental) that lie behind the ewe-related components: litter size and maternal abilities, which highly influence lamb meat production.

\section{MATERIAL AND METHODS}

\subsection{Animal material}

Data correspond to weights at birth and at 30,60 and 90 days of age of 4425 lambs, and 3355 litters at lambing of 964 ewes, taken between 1987 and 1995. This population is an experimental flock of the 'Centro de Selección de Ganado Merino' located in Hinojosa del Duque in the province of Cordoba (south of Spain). The flock is composed of six lines. Lines 1-5 are subflocks of animals derived from ewes purchased from five different sites. Line 6 is actually an amalgam of animals descended from unintentional crosses between lines 1 to 5 , and animals with uncertain parentage. All the animals were kept under a semi-intensive husbandry system, with approximately one lambing per year. Lambs stayed with their mothers until they were sold at an age close to 100 days. Lambs were weighed at birth, and thereafter, once a month until they were about 100 days old. Most of the lambs had their parents registered, except some animals from line 6 . The founder ewes have unknown parents and only have records of the litters they produced in the experimental flock. The animals with records on weights only are lambs (males and females) sold before the reproductive age, plus the rams born in the experimental flock and used afterwards as sires (table $l$ ). 
Table I. General structure of the data set.

\begin{tabular}{lr}
\hline Number of animals with records on litter size only & 454 \\
Number of animals with records on weights only & 3915 \\
Number of animals with records on both traits & 510 \\
Number of single lambings & 2096 \\
Number of twinnings & 1238 \\
Number of triple (or larger) lambings & 21 \\
Average number of litters per ewe & 3.5 \\
Maximum number of litters per ewe & 10 \\
Number of registered sires & 126 \\
Number of registered grandsires & 121 \\
Number of registered dams & 964 \\
Number of registered granddams with records on litter size & 449 \\
Number of registered granddams with records on weights & 192 \\
Number of inbred animals & 169 \\
Average inbreeding coefficient (\%) & 2.6 \\
Average litter size (lambs per ewe per lambing) & 1.4 \\
Average birth weight (kg) & 3.8 \\
Average 30-day weight (kg) & 11.5 \\
Average 60-day weight (kg) & 18.6 \\
Average 90-day weight (kg) & 27.7 \\
\hline
\end{tabular}

\subsection{Statistical analysis}

The estimation of variance components was carried out using the DFREML package [19], a derivative-free based algorithm for restricted maximum likelihood (REML: Patterson and Thompson [21]). Sampling errors of estimates were obtained using a quadratic approximation to the likelihood surface, an option available through the same package [19]. The use of REML, however, assumes that the analysed variables (traits) follow a normal distribution. While this assumption is correct for weight traits, the fact that litter size is a categorical variable makes the analysis improper with that algorithm. Non-linear techniques have been developed for a correct analysis, and a complete review can be found in Foulley and Manfredi [9]. Nevertheless, several studies have shown that the non-linear techniques, when applied to non-normal variables, outperform the linear techniques only in special cases, e.g. the variable under analysis is binary with a low incidence $[12,14,16-18,20,23,25]$. In the most recent work, the conclusion is still the same: although a non-linear method, under certain conditions, yields higher estimates of heritability [16], from a practical point of view (predictive abilities) both methods show the same performance [17]. In the present work, the analysis was carried out using a linear methodology. However, the integer scores of litter size were transformed into normal scores [24] in order to reduce complications related to the estimation of correlations between litter size and weight assuming a linear layout. A single trait analysis for each trait, and a bivariate analysis, where litter size was 
always present while each weight trait was included once, were applied according to the following linear models:

- single trait analyses:

$$
\begin{aligned}
& \mathbf{w}=\boldsymbol{X}_{1} \boldsymbol{\beta}_{1}+\boldsymbol{D} \boldsymbol{u}_{d}+\mathbf{M} \mathbf{u}_{m}+\mathbf{N n}+\boldsymbol{e}_{1} \\
& \mathbf{l} \mathbf{s}=\boldsymbol{X}_{2} \boldsymbol{\beta}_{2}+\mathbf{Z a}+\boldsymbol{H} \boldsymbol{p}+\boldsymbol{e}_{2}
\end{aligned}
$$

- bivariate analysis:

$$
\begin{aligned}
{\left[\begin{array}{l}
\boldsymbol{w} \\
\mathbf{l} s
\end{array}\right]=\left[\begin{array}{cc}
\boldsymbol{X}_{1} & \mathbf{0} \\
\mathbf{0} & \boldsymbol{X}_{2}
\end{array}\right]\left[\begin{array}{l}
\boldsymbol{\beta}_{1} \\
\boldsymbol{\beta}_{2}
\end{array}\right]+\left[\begin{array}{cc}
\boldsymbol{D} & \mathbf{0} \\
\mathbf{0} & \boldsymbol{Z}
\end{array}\right]\left[\begin{array}{c}
\mathbf{u}_{d} \\
\mathbf{a}
\end{array}\right] } \\
+\left[\begin{array}{cc}
\boldsymbol{M} & \mathbf{0} \\
\mathbf{0} & \mathbf{0}
\end{array}\right]\left[\begin{array}{c}
\mathbf{u}_{m} \\
\mathbf{0}
\end{array}\right]+\left[\begin{array}{cc}
\boldsymbol{N} & \mathbf{0} \\
\mathbf{0} & \boldsymbol{H}
\end{array}\right]\left[\begin{array}{l}
\boldsymbol{n} \\
\boldsymbol{p}
\end{array}\right]+\left[\begin{array}{l}
\boldsymbol{e}_{1} \\
\boldsymbol{e}_{2}
\end{array}\right]
\end{aligned}
$$

with

$$
E\left[\begin{array}{c}
\boldsymbol{w} \\
\text { ls }
\end{array}\right]=\left[\begin{array}{c}
\boldsymbol{X}_{1} \boldsymbol{\beta}_{1} \\
\boldsymbol{X}_{2} \boldsymbol{\beta}_{2}
\end{array}\right] \quad E\left[\begin{array}{c}
\boldsymbol{u}_{d} \\
\boldsymbol{u}_{m} \\
\boldsymbol{a} \\
\boldsymbol{n} \\
\boldsymbol{p} \\
\boldsymbol{e}_{1} \\
\boldsymbol{e}_{2}
\end{array}\right]=\left[\begin{array}{l}
0 \\
0 \\
0 \\
0 \\
0 \\
0 \\
0
\end{array}\right]
$$

$\operatorname{Var}(\mathbf{w})=\boldsymbol{D} \boldsymbol{A} \boldsymbol{D}^{\prime} \sigma_{d}^{2}+\boldsymbol{M} \mathbf{A} \boldsymbol{M}^{\prime} \sigma_{m}^{2}+\left(\boldsymbol{D A} \boldsymbol{M}^{\prime}+\boldsymbol{M} \boldsymbol{A} \boldsymbol{D}^{\prime}\right) \sigma_{d m}+\mathbf{N} \boldsymbol{N}^{\prime} \sigma_{n}^{2}+\mathbf{I} \sigma_{e_{1}}^{2}$

$\operatorname{Var}(\mathbf{l} \mathbf{s})=\boldsymbol{Z} \boldsymbol{A} \boldsymbol{Z}^{\prime} \sigma_{a}^{2}+\boldsymbol{H H}^{\prime} \sigma_{p}^{2}+\mathbf{I} \sigma_{e_{2}}^{2}$

$\operatorname{Cov}(\boldsymbol{w}, \boldsymbol{l s})=\boldsymbol{D} \boldsymbol{A} \boldsymbol{Z}^{\prime} \sigma_{d a}+\mathbf{M} \mathbf{A} \boldsymbol{Z}^{\prime} \sigma_{m a}+\boldsymbol{N} \boldsymbol{H}^{\prime} \sigma_{n p}$

and

$$
\operatorname{Var}\left[\begin{array}{c}
\boldsymbol{u}_{d} \\
\boldsymbol{i}_{m} \\
\mathbf{a} \\
\boldsymbol{n} \\
\boldsymbol{p} \\
\boldsymbol{e}_{1} \\
\boldsymbol{e}_{2}
\end{array}\right]=\left[\begin{array}{ccccccc}
\boldsymbol{A} \sigma_{d}^{2} & \boldsymbol{A} \sigma_{d m} & \boldsymbol{A} \sigma_{d a} & \mathbf{0} & \mathbf{0} & \mathbf{0} & \mathbf{0} \\
\boldsymbol{A} \sigma_{d m} & \boldsymbol{A} \sigma_{m}^{2} & \boldsymbol{A} \sigma_{m a} & \mathbf{0} & \mathbf{0} & \mathbf{0} & \mathbf{0} \\
\boldsymbol{A} \sigma_{d a} & \boldsymbol{A} \sigma_{m a} & \boldsymbol{A} \sigma_{a}^{2} & \mathbf{0} & \mathbf{0} & \mathbf{0} & \mathbf{0} \\
\mathbf{0} & \mathbf{0} & \mathbf{0} & \boldsymbol{I} \sigma_{n}^{2} & \boldsymbol{I} \sigma_{n p} & \mathbf{0} & \mathbf{0} \\
\mathbf{0} & \mathbf{0} & \mathbf{0} & \boldsymbol{I} \sigma_{n p} & \boldsymbol{I} \sigma_{p}^{2} & \mathbf{0} & \mathbf{0} \\
\mathbf{0} & \mathbf{0} & \mathbf{0} & \mathbf{0} & \mathbf{0} & \boldsymbol{I} \sigma_{e_{1}}^{2} & \mathbf{0} \\
\mathbf{0} & \mathbf{0} & \mathbf{0} & \mathbf{0} & \mathbf{0} & \mathbf{0} & \boldsymbol{I} \sigma_{\boldsymbol{e}_{2}}^{2}
\end{array}\right]
$$

where $\boldsymbol{w}$ is birth weight, 30-day weight, 60-day weight or 90 -d weight, $\mathbf{l s}$ is litter size, $\beta_{1}$ are fixed effects affecting weights (line, sex, type of birth, age of dam and year-season of birth), $\boldsymbol{\beta}_{2}$ are fixed effects affecting litter size (line, age of ewe and year-season of lambing). The individual coefficient of inbreeding was included as a covariate for all traits. Numbers of animals by level of fixed factors are shown in table II. The random factors affecting weights were: direct 
Table II. Number of lambs per level for each fixed factor.

\begin{tabular}{|c|c|c|c|c|c|c|c|}
\hline \multicolumn{2}{|c|}{ Line } & Sex & \multicolumn{2}{|c|}{ Type of birth } & \multicolumn{2}{|c|}{ Year of lambing } & Age of dam \\
\hline 1 & $(911)$ & males $\quad(2247)$ & singles & $(2$ 102) & 1987 & $(299)$ & 1 year $(166)$ \\
\hline 2 & $(315)$ & Females (2 178) & twins & $(2268)$ & 1988 & $(469)$ & 2 years $(686)$ \\
\hline 3 & $(676)$ & & Triplets or more & (55) & 1989 & $(463)$ & 3 years $(779)$ \\
\hline 4 & $(356)$ & & & & 1990 & $(533)$ & 4 years $(718)$ \\
\hline & $(729)$ & & & & 1991 & $(666)$ & 5 years $(647)$ \\
\hline \multirow{5}{*}{\multicolumn{2}{|c|}{$6(1438)$}} & & & & 1992 & $(592)$ & 6 years $(560)$ \\
\hline & & & & & 1993 & $(366)$ & 7 years $(401)$ \\
\hline & & & & & 1994 & $(562)$ & 8 years $(258)$ \\
\hline & & & & & 1995 & $(475)$ & 9 years $(157)$ \\
\hline & & & & & & & 10 years $(53)$ \\
\hline
\end{tabular}

additive effects $u_{d}$ with variance $\sigma_{d}^{2}$, maternal additive effect $u_{m}$ with variance $\sigma_{m}^{2}$ (the additive components have a covariance $\sigma_{d m}$ ), maternal permanent environmental effects $n$ with variance $\sigma_{n}^{2}$ and temporary environmental effects $e_{1}$ with variance $\sigma_{e 1}^{2}$. The random factors affecting litter size were: additive effects $a$ with variance $\sigma_{a}^{2}$, permanent environmental effects $p$ with variance $\sigma_{p}^{2}$ and temporary environmental effects $e_{2}$ with variance $\sigma_{e 2}^{2}$. Covariances between litter size and weights were due to additive covariance of litter size with direct effects $\sigma_{d a}$ and with maternal effects $\sigma_{m a}$ on weights, and to permanent environmental covariance between litter size and weights $\sigma_{n p}$. The temporary environmental covariance between litter size and weights was set to zero, because litter size and weights were recorded at quite different times for the same animal. Effectively, the last weight was recorded when the lamb was about 100 days old, while the first record of litter size was obtained at the earliest when the same animal was 1 year old. $\boldsymbol{X}_{1}, \boldsymbol{X}_{2}, \boldsymbol{D}, \boldsymbol{M}, \boldsymbol{N}$ and $\boldsymbol{H}$ are known incidence matrices, $\boldsymbol{A}$ is the numerator relationship matrix and $\boldsymbol{I}$ is an identity matrix. Individual inbreeding coefficients [28] were obtained with a Fortran77 program applying the algorithm of Quaas [22].

\section{RESULTS AND DISCUSSION}

Table III presents the results of single trait analyses. Weight traits showed direct heritabilities lower than estimates obtained in other breeds raised under Spanish managerial conditions $[13,15]$. Heritability of litter size showed a similar value to figures reported by Gabiña [10]. The additive maternal component seems to be important only till the lambs were 60 days old. However, maternal permanent environmental effect was of some significance for birth weight only. This environmental effect was also low for litter size. The additive correlation between direct and maternal effects for weights, though negative in some cases, was low. The values obtained do not fully agree with those obtained by, among others, Analla et al. [1] in Segureña lambs, where this correlation was always negative and strong (about -0.6 ). The estimates obtained suggest that the additive maternal effects, with higher heritability, could be easily improved by genetic selection, at least for birth weight and 30-day weight, without negative influence on direct effects whose heritability of which was low, and because 
Table III. Estimates along with approximate sampling errors of direct $\left(h^{2}\right)$ and maternal $\left(\mathrm{m}^{2}\right)$ additive genetic variance, covariance $\left(h^{m}\right)$ between both additive components and permanent environmental variance $\left(c^{2}\right)$ expressed as percentages of the total variance $\left(\sigma^{2}\right)$, obtained with single trait analyses.

\begin{tabular}{lccccr}
\hline Trait & $h^{2}$ & $m^{2}$ & $h m^{\mathrm{a}}$ & $c^{2}$ & \multicolumn{1}{c}{$\sigma^{2}$} \\
\hline Birth weight & $0.05 \pm 0.02$ & $0.29 \pm 0.01$ & $-0.02 \pm 0.01(-0.21)$ & $0.11 \pm 0.03$ & 0.336 \\
30-day weight & $0.04 \pm 0.01$ & $0.22 \pm 0.01$ & $-0.02 \pm 0.01(-0.27)$ & $0.01 \pm 0.02$ & 2.888 \\
60-day weight & $0.08 \pm 0.04$ & $0.16 \pm 0.03$ & $-0.00 \pm 0.03(-0.01)$ & $0.03 \pm 0.02$ & 7.028 \\
90-day weight & $0.13 \pm 0.05$ & $0.04 \pm 0.03$ & $0.01 \pm 0.02(0.07)$ & $0.06 \pm 0.02$ & 13.404 \\
Litter size & $0.13 \pm 0.04$ & - & - & $0.05 \pm 0.06$ & 0.240 \\
\hline
\end{tabular}

${ }^{\text {a }}$ Values inside parenthesis are the corresponding correlations.

the genetic correlations involved, although negative, were also low. Litter size could also show some response to selection. Thus, Merino sheep could be submitted to selection to improve female litter size and maternal abilities, giving rise to an excellent ewe breed to be used in terminal crosses with improved ram breeds, such as Ile de France, Berrichon du Cher, since this type of cross is commonly used in the region where the breed is raised.

Table $I V$ shows the estimates of former parameters obtained in bivariate analyses. They were very similar to those obtained in single trait analyses. This is partly due to the fact that correlations between litter size and weights were low. Therefore, the information contributed by litter records to weights and vice versa was of little importance. This was partially confirmed by the results presented in tables $V$ and $V I$. In table $V$ additive genetic, phenotypic and permanent environmental correlations between litter size and weights are reported. The phenotypic correlations were practically zero, and the additive genetic correlation was higher between litter size and birth weight than those between litter size and later weights. This does not agree with the increasing trend of genetic correlations with age, as reported by Analla et al. [2]. The values obtained in the present study were higher between litter size and birth weight, but lower between litter size and the other weights. Although, the models used in both studies are different, they remain, always, gross simplifications of a quite complicated reality. This highlights the fact that estimation of such components is not a simple task. In particular, the maternal components are surrounded by controversy about the real origin of the correlation between direct and maternal components [27]. The widespread theoretical model used in this study was proposed initially by Dickerson [8] and developed by Willham [26]. Such a model assumes a unique correlation of additive origin. However, Hohenboken and Brinks [11] added an environmental correlation between direct and maternal effects, which has been shown to be different from zero, at least in weaning weight of beef cattle $[5,6]$. On the other hand, the use of a linear layout for litter size could probably be responsible for some inconsistency in the results. Therefore, a more rigorous approach considering all the foregoing flaws would probably give better results.

The permanent environmental correlations were similar to additive genetic correlations and followed the same trend. This was probably due to the fact that an important part of the permanent environmental effects is of genetic 
Table IV. Estimates along with approximate sampling error of direct $\left(h^{2}\right)$ and maternal $\left(\mathrm{m}^{2}\right)$ additive genetic variance and permanent environmental variance $\left(c^{2}\right)$ expressed as percentages of the total variance $\left(\sigma^{2}\right)$, obtained with bivariate analyses of litter size and weights.

\begin{tabular}{lcccr}
\hline Trait & $h^{2}$ & $m^{2}$ & $c^{2}$ & $\sigma^{2}$ \\
\hline Birth weight & $0.04 \pm 0.02$ & $0.27 \pm 0.01$ & $0.11 \pm 0.02$ & 0.357 \\
30-day weight & $0.06 \pm 0.01$ & $0.20 \pm 0.01$ & $0.01 \pm 0.01$ & 2.914 \\
60-day weight & $0.09 \pm 0.04$ & $0.17 \pm 0.02$ & $0.03 \pm 0.02$ & 7.249 \\
90-day weight & $0.14 \pm 0.03$ & $0.05 \pm 0.03$ & $0.07 \pm 0.02$ & 14.017 \\
Litter size & $0.14 \pm 0.05^{\mathrm{a}}$ & - & $0.05 \pm 0.06^{\mathrm{a}}$ & $0.241^{\mathrm{a}}$ \\
\hline
\end{tabular}

a Average of four estimates.

Table V. Estimates along with approximate sampling errors of additive genetic, permanent environmental and phenotypic correlations between litter size and weights, obtained with bivariate analyses.

\begin{tabular}{lcccc}
\hline $\begin{array}{l}\text { Correlations between litter } \\
\text { size and }\end{array}$ & $\begin{array}{c}\text { Birth } \\
\text { weight }\end{array}$ & $\begin{array}{c}\text { 30-day } \\
\text { weight }\end{array}$ & $\begin{array}{c}60 \text {-day } \\
\text { weight }\end{array}$ & $\begin{array}{c}\text { 90-day } \\
\text { weight }\end{array}$ \\
\hline Additive genetic & $0.58 \pm 0.12$ & $0.19 \pm 0.07$ & $0.15 \pm 0.11$ & $0.13 \pm 0.08$ \\
Permanent environmental & $0.57 \pm 0.13$ & $0.18 \pm 0.09$ & $0.10 \pm 0.06$ & $0.08 \pm 0.04$ \\
Phenotypic & $0.09 \pm 0.10$ & $0.03 \pm 0.04$ & $0.05 \pm 0.03$ & $0.04 \pm 0.02$ \\
\hline
\end{tabular}

Table VI. Estimates along with approximate sampling errors of correlations between additive genetic direct and maternal effects for weights $\left(r_{w w}\right)$, and between additive effects for litter size and maternal effects for weight $\left(r_{l w}\right)$, obtained with bivariate analyses.

\begin{tabular}{lcccc}
\hline Correlations & Birth & 30-day weight & 60-day weight & 90-day weight \\
\hline$r_{w w}$ & $-0.23 \pm 0.04$ & $-0.24 \pm 0.05$ & $-0.02 \pm-0.02$ & $0.07 \pm 0.06$ \\
$r_{l w}$ & $-0.06 \pm 0.07$ & $-0.05 \pm 0.10$ & $-0.01 \pm 0.03$ & $0.03 \pm 0.10$ \\
\hline
\end{tabular}

origin (dominance and epistasis) and some correlation could exist between those genetic effects and the additive ones, in spite of the fact that the infinitesimal model used assumes that dominant and epistatic effects are negligible.

Table VI shows the additive genetic correlations between litter size and maternal effects for weights. The values obtained were close to zero. This means that genetic manipulations of litter size would have no influence on maternal effects for growth of the lambs, and a probable low but positive influence on the lambs' own capacity for growth. The increase in litter size, however, is known to have an undesirable negative side effect on lamb weight. Lambs from multiple lambings show a lower expression for growth, at least until weaning, and have smaller final weights [3]. Therefore, a global consideration of all these factors should be taken into account when preparing the selection scheme for the Spanish Merino breed. But, unlike in other local breeds, common use of terminal crosses in the case of the Merino will condition the elaboration of the 
strategy for meat improvement to be chosen by breeders. In this sense, breeders should focus their efforts on increasing litter size and maternal abilities, since these traits would show a response to selection as mentioned above, while the problem of lamb weights is resolved by the use of the terminal cross.

\section{CONCLUSIONS}

The results obtained in this study show that the additive genetic correlation between litter size and maternal abilities was practically zero. The additive genetic correlation of direct effects was low and similar to the correlation of permanent environmental effects between litter size and weights. This suggests that the local Merino breed could be oriented towards the production of high quality females (with higher litter size and better maternal abilities) to be used in terminal crosses for lamb production in Spain. Nevertheless, these conclusions should be taken with some caution, as the models are simplistic descriptions of the reality; and this simplification was probably taken to the limit in the present case, in view of the models and the methodology used. Hence, further studies with a larger data set, and probably using other approaches, should be carried out to confirm the parameters' estimates obtained and the deductions herewith outlined.

\section{ACKNOWLEDGEMENT}

The first author greatly appreciates the financial support of the University of Cordoba, during his stay at the 'Laboratorio de Fisiogenética Animal, ETSIAM'.

\section{REFERENCES}

[1] Analla M., Muñoz-Serrano A., Cruz J.M., Serradilla J.M., Estimation of genetic parameters of growth traits in Segureña lambs, J. Anim. Breed. Genet. 112 (1995) 183-190.

[2] Analla M., Muñoz-Serrano A., Serradilla J.M., Analysis of the genetic relationship between litter size and weight traits in Segureña sheep, Can. J. Anim. Sci. 77 (1997) 17-21.

[3] Black J.L., Growth and development of lambs, in: Haresign W. (Ed.), Sheep Production, Butterworths, London, 1983, pp. 21-58.

[4] Bradford G.E., The role of maternal effects in animal breeding: VII - Maternal effects in sheep, J. Anim. Sci. 35 (1972) 1324-1334.

[5] Brukner C.M., Slanger W.D., Symmetric differences squared and analysis of variance procedures for estimating genetic and environmental variances and covariances for beef cattle weaning weight: II - Estimates from a data set, J. Anim. Sci. 63 (1986) 1794-1803.

[6] Cantet R.J.C., Kress D.D., Anderson D.C., Doornobs D.E., Burfening P.J., Blackwell R.L., Direct and maternal variances and covariances and maternal phenotypic effects on preweaning growth of beef cattle, J. Anim. Sci. 66 (1988) 648-660.

[7] Davis G.P., Kinghorn B.P., Genetic and phenotypic parameters for growth, wool production and reproduction traits in a line of Merino sheep, in: Dickerson G.E., Johnson R.K. (Eds.), Proceedings of the 3rd World Congress on Genetics Applied to Livestock Production, Lincoln, vol. 11, 1986, pp. 145-150.

[8] Dickerson G.E., Composition of hog carcasses as influenced by heritable differences in rate and economy of gain, Iowa State College of Agriculture Res. Bull. 354 (1947) 489-524. 
[9] Foulley J.L., Manfredi E., Approches statistiques de l'évaluation génétique des reproducteurs pour des caractères binaires à seuils, Genet. Sel. Evol. 23 (1991) 309 338.

[10] Gabiña D., Improvement of reproductive performance of Rasa Aragonesa flocks in frequent lambing systems. II-Repeatability and heritability of sexual precocity, fertility and litter size. Selection strategies, Livest. Prod. Sci. 22 (1989) 87-98.

[11] Hohenbocken W.D., Brinks J.S., Relationship between direct and maternal effects on growth in Herefords: II - Partition of covariance between relatives, J. Anim. Sci. 32 (1971) 26-34.

[12] Jensen J., Sire evaluation for type traits using linear and nonlinear procedures, Livest. Prod. Sci. 15 (1986) 165-171.

[13] Jurado J.J., Alonso A., Alenda R., Selection for growth in a Spanish Merino flock, J. Anim. Sci. 72 (1994) 1433-1440.

[14] Mäntysaari E.A., Quaas R.L., Gröhn Y.T., Simulation study on covariance components estimation for two binary traits in an underlying continuous scale, J. Dairy Sci. 75 (1991) 580-591.

[15] Maria G.A., Boldman K.G., Van Vleck L.D., Estimates of variances due to direct and maternal effects for growth traits of Romanov sheep, J. Anim. Sci. 71 (1993) 845-849.

[16] Matos C.A.P., Thomas D.L., Gianola D., Templman J., Young L.D., Genetic analysis of discrete reproductive traits in sheep using linear and non linear models: I-Estimation of genetic parameters, J. Anim. Sci. 75 (1997) 76-87.

[17] Matos C.A.P., Thomas D.L., Gianola D., Pérez-Enciso M., Young L.D., Genetic analysis of discrete reproductive traits in sheep using linear and non linear models: II - Goodness of fit and predictive ability, J. Anim. Sci. 75 (1997) 88-94.

[18] Meijering A., Gianola D., Linear versus nonlinear methods of sire evaluation for categorical traits: a simulation study, Genet. Sel. Evol. 17 (1985) 115-132.

[19] Meyer K., DFREML version 2.1 user's notes, Animal Genetics and Breeding Unit, University of New England, Armidale, Australia, 1993.

[20] Olesen I., Pérez-Enciso M., Gianola D., Thomas D.L., A comparison of normal and nonnormal mixed models for number of lambs born in Norwegian sheep, J. Anim. Sci. 72 (1994) 1166-1173.

[21] Patterson H.D., Thompson R., Recovery of interblock information when block sizes are unequal, Biometrika 58 (1971) 545-558.

[22] Quaas R.L., Computing the diagonal elements and inverse of a large numerator relationship matrix, Biometrics 32 (1976) 949-953.

[23] Renand G., Janss L.L.G., Gaillard J., Sire evaluation for direct effects on dystocia by linear and threshold models, in: Hill W.G., Thompson R., Wolliams J.A. (Eds.), Proceedings of the 4th World Congress on Genetics Applied to Livestock Production, Edinburgh, vol. 13, 1990, pp. 465-467.

[24] Snell E.J., A scaling procedure for ordered categorical data, Biometrics 20 (1964) 594-607.

[25] Weller J.I., Misztal I., Gianola D., Genetic analysis of dystocia and calf mortality in Israeli-Holstein by threshold and linear models, J. Dairy Sci. 71 (1988) 2491-2501.

[26] Willham R.L., The covariance between relatives for characters composed of components contributed by related individuals, Biometrics 19 (1963) 18-27.

[27] Willham R.L., Problems in estimating maternal effects, Livest. Prod. Sci. 7 (1980) 18-27.

[28] Wright S., Coefficients of inbreeding and relationship, Am. Nat. 56 (1922) $330-338$. 